\title{
Modic changes of the cervical spine:TI slope and its impact on axial neck pain
}

This article was published in the following Dove Press journal:

Journal of Pain Research

24 August 2017

Number of times this article has been viewed

Jia $L i^{1,2^{*}}$

Shuhui Qin ${ }^{1,2^{*}}$

Yongqian $\mathrm{Li}^{1,2}$

Yong Shen ${ }^{1,2}$

'Department of Orthopaedic Surgery, The Third Hospital of Hebei

Medical University, Shijiazhuang,

Peoples Republic of China; ${ }^{2}$ The

Key Laboratory of Orthopedic

Biomechanics of Hebei Province,

The Third Hospital of Hebei Medical

University, Shijiazhuang, People's

Republic of China

*These authors contributed equally to this work

Correspondence: Yong Shen

Department of Orthopaedic Surgery,

The Third Hospital of Hebei Medical

University, 139 Ziqiang Road,

Shijiazhuang, 05005I, People's Republic

of China

Tel +863 II 88602016

Fax +8631188602015

Email docshenyong@163.com
Background: The purpose of the research was to evaluate cervical sagittal parameters on magnetic resonance imaging (MRI) in patients with Modic changes and its impact on axial neck pain. Methods: This study consisted of 266 consecutive asymptomatic or symptomatic patients with Modic changes, whose average age was 50.9 \pm 12.6 years from January 2015 to December 2016. Cervical sagittal parameters included sagittal alignment of the cervical spine (SACS), T1 slope, thoracic inlet angle (TIA), and neck tilt (NT). The Modic changes group was compared with an asymptomatic control group of 338 age- and gender-matched adults.

Results: In the Modic changes group, T1 slope was significantly higher $\left(25.8^{\circ} \pm 6.3^{\circ}\right)$ compared with that in the control group $\left(22.5^{\circ} \pm 6.8^{\circ}\right)(P=0.000)$. However, there was no significant difference of the NT, TIA, and SACS between the two groups. Patients in the Modic changes group were more likely to have experienced historical axial neck pain compared with the control group $(P=0.000)$. With regard to the disc degeneration, it indicated that the disc in the Modic changes group had more severe disc degeneration $(P=0.032)$.

Conclusion: T1 slope in the Modic changes group was significantly higher compared to that of the control group. The findings suggested that a higher T1 slope with broken compensation of cervical sagittal mechanism may be associated with the development of Modic changes in the cervical spine.

Keywords: Modic changes, T1 slope, axial neck pain, cervical spine

\section{Introduction}

Modic changes describe vertebral endplate and bone marrow lesions on magnetic resonance imaging (MRI), which are classified into three types. "Modic-1 changes" represent marrow edema and inflammatory phase; "Modic- 2 changes" appear as fatty replacement of the subchondral bone and marrow; "Modic-3 changes" represent subchondral bone sclerosis. ${ }^{1-3}$ Several studies have evaluated the role of Modic changes in relation to low back pain. ${ }^{4,5}$ Määttä et al found Modic changes were an independent risk factor for low back pain in middle-aged women. ${ }^{6}$ Kääpä et al concluded that Modic changes directly correlate with clinical symptoms. ${ }^{7}$

Axial neck pain, including neck pain, stiff neck or dullness, is a multifactorial condition. Many studies have reported that degenerative disc disease (lesions of the disc and facet joints) were significant risk factors leading to the symptoms. ${ }^{8} 9$ Patients with Modic changes were associated with higher risk of developing neck pain. Recently, Sheng-yun et al found a significant relationship between Modic changes and neck pain. ${ }^{10}$

However, the natural evolution and risk factors of Modic changes and their clinical significance are not completely understood at the moment. Cervical sagittal parameters 
include thoracic inlet angle (TIA), neck tilt (NT), and T1 slope, which are similar to pelvic incidence (PI) and impact the cervical sagittal alignment. ${ }^{11,12} \mathrm{~T} 1$ slope and TIA are significant anatomical landmarks which can be used to assess the cervical sagittal balance. ${ }^{13}$

To the best of our knowledge, no one has reported the effect of the cervical sagittal balance on patients with Modic changes and axial neck pain. The hypothesis is that cervical sagittal parameters have some relationship to Modic changes, which might be associated with axial neck pain. The purpose of the research was to evaluate cervical sagittal parameters on MRI in patients with Modic changes and their impact on axial neck pain.

\section{Methods}

\section{Study design}

In this study, we identified a total of 266 patients (120 males and 146 females) with Modic changes, whose average age was 50.9 \pm 12.6 years (range 30-63 years), from January 2015 to December 2016. In order to investigate whether cervical sagittal parameters were associated with a higher prevalence of Modic changes, we also collected MRI scans from 338 adults (162 men and 176 women) without Modic changes who underwent physical examination in the same period. The inclusion criteria were defined as patients who had available cervical MRI scans with or without nonspecific axial neck pain. The exclusion criteria were spinal infection, trauma, vertebral fracture, rheumatic disease, spinal tumors, and history of cervical surgery.

The Institutional Review Board of the Third Hospital of Hebei Medical University approved this study (approval no 2015-C006). The clinical investigations were conducted according to the principles expressed in the Declaration of Helsinki. Patient consent to review their medical records was not required, as all data were de-identified.

\section{MRI assessment}

Radiographic evaluation included MRI of the cervical spine. Two independent radiologists without knowledge of the clinical information assessed the radiographs. Modic changes of cervical spine on MRI were classified into none or Modic-1, 2 , or 3. The MRIs of the spinal cord were obtained using a spin echo sequence system for T1-weighted images and a fast spin echo sequence system for T1-weighted images. A cervical coil was used.

We measured the sagittal cervical parameters on MRI. The sagittal alignment of the cervical spine (SACS) was defined as the angle by the caudal endplates of $\mathrm{C} 2$ and $\mathrm{C} 7 \mathrm{in}$
MRI (Figure 1). T1 slope was measured as the angle between a horizontal line and cephalad endplate of T1 in MRI. NT was measured as an angle formed by a vertical line passing through the cephalad end of the sternum and a line connecting the center of the $\mathrm{T} 1$ cephalad endplate of and the cephalad end of the sternum. TIA was defined as T1 slope + NT (Figure 2).

Disc degeneration was assessed by the method of Schneiderman et al. ${ }^{14}$ Axial neck pain included neck pain, stiff neck or dullness.

\section{Statistical analysis}

Statistical analysis was performed using SPSS software (version 21.0; IBM Corporation, Armonk, NY, USA). The kappa statistic was used to evaluate the inter-observer and intra-observer reliability of the Modic changes (excellent: 0.81-1.0; substantial: 0.61-0.80; moderate: $0.41-0.60$; fair: $0.21-0.40$; slight: $0.0-0.20$; poor: less than 0.0 ). The significant difference of measurements between the Modic changes group and control group was analyzed using Student's $t$-test or Chi-square test. In all analysis, significance was defined as $P<0.05$. Results are presented as mean \pm SD.

\section{Results}

The inter-observer agreement with the Modic changes classification was 0.73 (substantial). The intra-observer agreement with the Modic changes classification was 0.81 (excellent).

Of patients with Modic changes, 65 patients (24.4\%) had Modic- 1 changes, 189 patients (71.1\%) had Modic-2 changes,

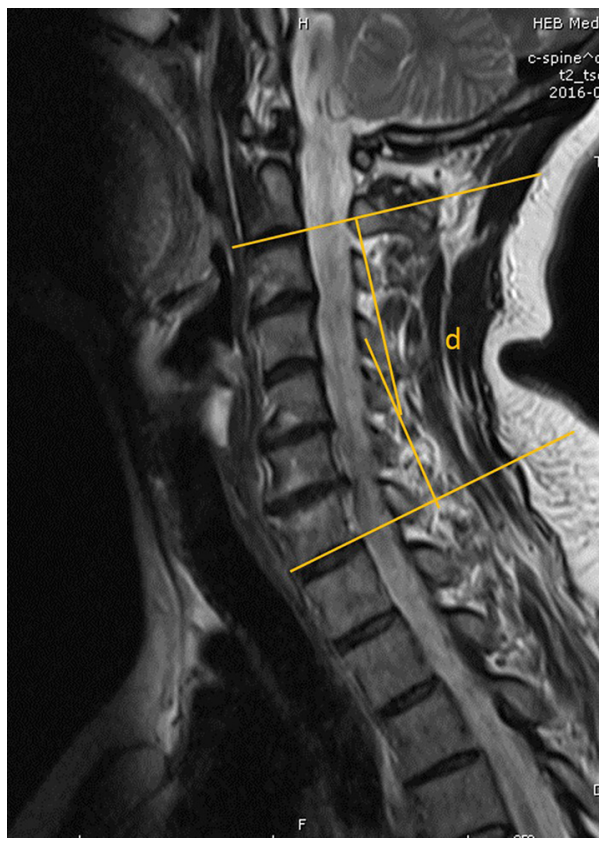

Figure I The sagittal alignment of the cervical spine was defined as the angle by the caudal endplates of $\mathrm{C} 2$ and $\mathrm{C} 7$ in magnetic resonance imaging (d). 


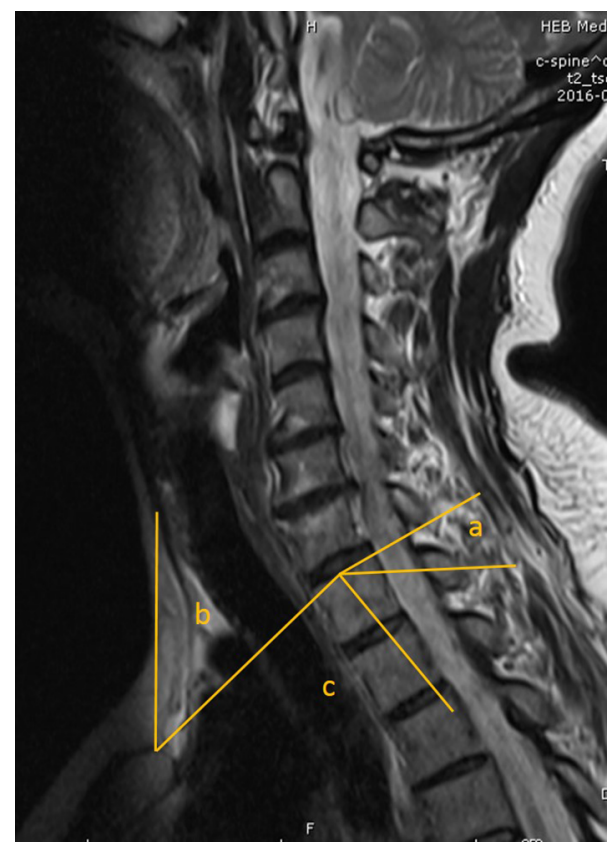

Figure $2 \mathrm{TI}$ slope was measured as the angle between a horizontal line and cephalad endplate of $\mathrm{TI}$ in magnetic resonance imaging (a). NT was defined as an angle formed by a vertical line passing through the upper end of the sternum and a line connecting the center of the TI cephalad endplate and the upper end of the sternum (b). TIA was defined as TIS + NT (c).

Abbreviations: NT, neck tilt; TIA, thoracic inlet angle; TIS, TI slope.

and 12 patients (4.5\%) had Modic-3 changes. Sixty-one patients $(35.5 \%)$ had Modic changes in more than one segmental level. In 1,330 motion cervical segments, 257 segments demonstrated Modic changes (19.3\%): Modic-1 changes in 70 segments (5.3\%), Modic-2 changes in 175 segments (13.2\%), and Modic-3 changes in 12 segments (1.0\%). Modic changes were most frequent at C5-6 followed by C6-7 and C4-5.

The comparison of the demographic characteristics of the Modic changes group and the control group was performed. The disc degeneration score and axial neck pain in the Modic changes group was significantly higher than the control group. Patients in the Modic changes group were more likely to have experienced historical axial neck pain (112 patients) compared with the control group (90 patients) $(P=0.000)$. According to disc degeneration, significant differences were revealed between the Modic changes group and the control group, which indicated that the disc in the Modic changes group had more severe disc degeneration $(P=0.032$ ) (Table 1$)$.

T1 slope in the Modic changes group was $25.8^{\circ} \pm 6.3^{\circ}$ and in the control group $22.5^{\circ} \pm 6.8^{\circ}(P=0.000)$. The difference of T1 slope between the Modic changes group and the control group was $3.3^{\circ}$. NT in Modic changes group was $50.2^{\circ} \pm 7.6^{\circ}$ and in the control group $52.3^{\circ} \pm 7.2^{\circ}$. TIA in the Modic changes group was $76.9^{\circ} \pm 8.2^{\circ}$ and in the control group $75.1^{\circ} \pm 7.9^{\circ}$. SACS in the Modic changes group was $12.8^{\circ} \pm 6.5^{\circ}$ and in the control group $11.5^{\circ} \pm 7.3^{\circ}$. However, there was no significant difference when comparing the NT, TIA, and SACS between the two groups (Table 2).

\section{Discussion}

The cervical spine has higher mobility and less load compared to the lumbar spine, which might also cause the disc degeneration and clinical symptoms. The cervical spine has higher global and segmental activities compared to the lumbar spine. Degenerative marrow changes on MRI also have a definite correlation with disc degeneration. The incidence of Modic changes in the lumbar spine is reported to be $19 \%$ and 59\%, with Modic- 1 and 2 changes being the most common. However, Modic changes are less in the cervical spine compared to the lumbar spine, with prevalence varying from $4.5 \%$ to $40.4 \%$. $^{4,10,15,16}$ Matsumoto et $\mathrm{al}^{17}$ and Mann et $\mathrm{al}^{18}$ demonstrated that Modic-2 changes in the cervical spine were the most common. Recently, Sheng-yun et al found Modic-2 changes were the most common and Modic-3 changes were the least common. ${ }^{10}$ In our study the prevalence of Modic-2 changes was more frequent and most common at C5-6 and C6-7, which was similar to other studies.

As we know, T1 slope is a critical issue similar to the PI and lumbar sagittal balance. The cervical sagittal balance is related to the T1 slope. Previous studies have compared various sagittal parameters obtained from radiographs and computed tomography (CT) scans. ${ }^{11,19,20}$ Jun et al demonstrated the strong correlation of sagittal parameters between cervical

Table I Demographic characteristics of the Modic changes group and the control group

\begin{tabular}{llll}
\hline & $\begin{array}{l}\text { Modic changes } \\
\text { group }\end{array}$ & $\begin{array}{l}\text { Control } \\
\text { group }\end{array}$ & P-value \\
\hline Age (years) & $50.9 \pm 12.6$ & $48.1 \pm 10.3$ & 0.186 \\
Gender $(\mathrm{M} / \mathrm{F})$ & $120 / 146$ & $162 / 176$ & 0.491 \\
Body mass index $\left(\mathrm{kg} / \mathrm{m}^{2}\right)$ & $23.8 \pm 3.3$ & $22.6 \pm 3.6$ & 0.192 \\
Disc degeneration score & $4.6 \pm 2.8$ & $2.2 \pm 2.5$ & 0.032 \\
Axial neck pain $(\mathrm{n})$ & 112 & 90 & 0.000 \\
\hline
\end{tabular}

Note: Data presented as mean \pm SD.

Abbreviations: $F$, female; $M$, male.

Table 2 Comparison of the TIA and SACS between the Modic changes group and the control group

\begin{tabular}{llll}
\hline & $\begin{array}{l}\text { Modic changes } \\
\text { group }\end{array}$ & $\begin{array}{l}\text { Control } \\
\text { group }\end{array}$ & P-value \\
\hline SACS & $12.8^{\circ} \pm 6.5^{\circ}$ & $11.5^{\circ} \pm 7.3^{\circ}$ & 0.377 \\
TI slope & $25.8^{\circ} \pm 6.3^{\circ}$ & $22.5^{\circ} \pm 6.8^{\circ}$ & 0.000 \\
Neck tilt & $50.2^{\circ} \pm 7.6^{\circ}$ & $52.3^{\circ} \pm 7.2^{\circ}$ & 0.271 \\
TIA & $76.9^{\circ} \pm 8.2^{\circ}$ & $75.1^{\circ} \pm 7.9^{\circ}$ & 0.106 \\
\hline
\end{tabular}

Note: Data presented as mean \pm SD.

Abbreviations: TIA, thoracic inlet angle; SACS, sagittal alignment of the cervical spine. 
radiographs and CT scans. For this reason, to avoid limitations of cervical radiographs, we chose MRI to perform this study. ${ }^{13}$

In the current study, patients in the Modic changes group were found to have a higher T1 slope than the control group. Previous studies confirmed that the large TIA increased T1 slope and finally increased SACS. ${ }^{11,13,19}$ Therefore, patients with Modic changes might have a greater SACS than those in the control group. However, SACS were statistically comparable in this study. There may be a damage compensation of cervical sagittal mechanism in the Modic changes group. Patients with higher T1 slope needed more cervical lordosis and energy expenditure to keep horizontal balance. The similar SACS have a different meaning. Patients in the Modic changes group come to have more horizontal or gravity direction, which may lead to kyphotic force.

Modic changes were impacted by the structural deterioration of the cervical discs caused by mechanical stress. The torsional forces led to the injury of cartilage endplates and bone marrow as a consequence of disc degeneration. The torsional forces and hyperactivity in the Modic changes group resulted in a sagittal imbalance and/or anterior translation of the axis of gravity. According to the similar SACS between the two groups, segmental kyphosis might be the reason. On the other hand, patients in the control group needed moderately lower SACS to keep cervical sagittal balance. Thus, as shown in our study, no significant variations in the other parameters were detected in the Modic changes group owing to the broken compensation mechanism by disc hyperactivity and loss of cervical lordosis.

In this study, we found Modic changes to be more common at C5-6 and C6-7, similar to other studies. Chaput et al found that C3-5 are subjected to increased stress, which may result in cervical degeneration and abnormal cervical translation. ${ }^{21}$ Therefore, it was demonstrated that higher T1 slope needed more cervical lordosis to keep horizontal balance, which caused more stress and hypermobility at the disc. The higher T1 slope suggested that an unusual mechanism influenced the incidence of Modic changes. However, this correlation was one of many factors, not a causal relationship.

Previous studies reported that Modic changes were associated with both disc degeneration and the presence of low back pain.,22 In our study, we also showed that the patients in the Modic changes group were significantly more likely to experience axial neck pain than those in the control group. The higher T1 slope might lead to cervical kyphosis, increasing the risk of endplate damage and disc degeneration. However, a causal relationship was not proven.

\section{Limitations}

The present study has some limitations. There was a lack of study on the relationship between the cervical parameter of Modic changes and disc degeneration. Owing to the retrospective nature of this study, it is difficult to control for the many variables inherent in patients with Modic changes. Furthermore, the possibility of selection bias exists. As we all know, Modic changes are a dynamic phenomenon, and their conversion in patients with $\mathrm{T} 1$ slope is still unknown. Therefore, a large scale follow-up study should be carried out to define the relationship between T1 slope and Modic changes.

\section{Conclusion}

T1 slope in Modic changes group was significantly higher compared to that of the control group. The findings suggested that a higher T1 slope with broken compensation of cervical sagittal mechanism may be associated with the development of Modic changes in the cervical spine.

\section{Disclosure}

The authors report no conflicts of interest in this work.

\section{References}

1. Modic MT, Masaryk TJ, Ross JS, Carter JR. Imaging of degenerative disk disease. Radiology. 1988;168(1):177-186.

2. Modic MT, Steinberg PM, Ross JS, Masaryk TJ, Carter JR. Degenerative disk disease: assessment of changes in vertebral body marrow with MR imaging. Radiology. 1988;166(1 Pt 1):193-199.

3. Schmid G, Witteler A, Willburger R, Kuhnen C, Jergas M, Koester O. Lumbar disk herniation: correlation of histologic findings with marrow signal intensity changes in vertebral endplates at MR imaging. Radiology. 2004;231(2):352-358.

4. Kuisma M, Karppinen J, Niinimaki J, et al. Modic changes in endplates of lumbar vertebral bodies: prevalence and association with low back and sciatic pain among middle-aged male workers. Spine (Phila Pa 1976). 2007;32(10):1116-1122.

5. Wu HL, Ding WY, Shen Y, Zhang YZ, Guo JK, Sun YP, Cao LZ. Prevalence of vertebral endplate modic changes in degenerative lumbar scoliosis and its associated factors analysis. Spine (Phila Pa 1976). 2012;37(23):1958-1964.

6. Määttä JH, Wadge S, MacGregor A, Karppinen J, Williams FM. Vertebral endplate (Modic) change is an independent risk factor for episodes of severe and disabling low back pain. Spine (Phila Pa 1976). 2015;40(15):1187-1193.

7. Kääpä E, Luoma K, Pitkäniemi J, Kerttula L, Grönblad M. Correlation of size and type of modic types 1 and 2 lesions with clinical symptoms: a descriptive study in a subgroup of patients with chronic low back pain on the basis of a university hospital patient sample. Spine (Phila Pa 1976). 2012;37(2):134-139.

8. Wagner SC, Formby PM, Kang DG, Van Blarcum GS, Cody JP, Tracey RW, Lehman RA Jr. Persistent axial neck pain after cervical disc arthroplasty: a radiographic analysis. Spine J. 2016;16(7):851-856.

9. Kawakami M, Tamaki T, Yoshida M, Hayashi N, Ando M, Yamada H. Axial symptoms and cervical alignments after cervical anterior spinal fusion for patients with cervical myelopathy. J Spinal Disord. 1999;12(1): $50-56$. 
10. Sheng-yun L, Letu S, Jian C, et al. Comparison of modic changes in the lumbar and cervical spine, in 3167 patients with and without spinal pain. PLoS One. 2014;9(12):e114993.

11. Lee SH, Kim KT, Seo EM, Suk KS, Kwack YH, Son ES. The influence of thoracic inlet alignment on the craniocervical sagittal balance in asymptomatic adults. J Spinal Disord Tech. 2012;25(2):E41-E47.

12. Park JH, Cho CB, Song JH, Kim SW, Ha Y, Oh JK. T1 slope and cervical sagittal alignment on cervical CT radiographs of asymptomatic persons. $J$ Korean Neurosurg Soc. 2013;53(6):356-359.

13. Jun HS, Chang IB, Song JH, Kim TH, Park MS, Kim SW, Oh JK. Is it possible to evaluate the parameters of cervical sagittal alignment on cervical computed tomographic scans? Spine (Phila Pa 1976). 2014;39(10):E630-636.

14. Schneiderman G, Flannigan B, Kingston S, Thomas J, Dillin WH, Watkins RG. Magnetic resonance imaging in the diagnosis of disc degeneration: correlation with discography. Spine (Phila Pa 1976). 1987;12(3):276-281.

15. Kuisma M, Karppinen J, Niinimaki J, Kurunlahti M, Haapea M, Vanharanta $\mathrm{H}$, Tervonen $\mathrm{O}$. A three-year follow-up of lumbar spine endplate (Modic) changes. Spine (Phila Pa 1976). 2006;31(15):1714-1718.

16. Rahme R, Moussa R. The modic vertebral endplate and marrow changes: pathologic significance and relation to low back pain and segmental instability of the lumbar spine. AJNR Am J Neuroradiol. 2008;29(5):838-842.
17. Matsumoto M, Okada E, Ichihara D, et al. Modic changes in the cervical spine: prospective 10-year follow-up study in asymptomatic subjects. J Bone Joint Surg Br. 2012;94(5):678-683.

18. Mann E, Peterson CK, Hodler J. Degenerative marrow (modic) changes on cervical spine magnetic resonance imaging scans: prevalence, interand intra-examiner reliability and link to disc herniation. Spine (Phila Pa 1976). 2011;36(14):1081-1085.

19. Jang JS, Lee SH, Min JH, Kim SK, Han KM, Maeng DH. Surgical treatment of failed back surgery syndrome due to sagittal imbalance. Spine (Phila Pa 1976). 2007;32(26):3081-3087.

20. Jun HS, Kim JH, Ahn JH, et al. T1 slope and degenerative cervical spondylolisthesis. Spine (Phila Pa 1976). 2015;40(4):E220-E226.

21. Chaput CD, Allred JJ, Pandorf JJ, Song J, Rahm MD. The significance of facet joint cross-sectional area on magnetic resonance imaging in relationship to cervical degenerative spondylolisthesis. Spine J. 2013;13(8):856-861.

22. Kjaer P, Korsholm L, Bendix T, Sorensen JS, Leboeuf-Yde C. Modic changes and their associations with clinical findings. Eur Spine J. 2006;15(9):1312-1319.
Journal of Pain Research

\section{Publish your work in this journal}

The Journal of Pain Research is an international, peer reviewed, open access, online journal that welcomes laboratory and clinical findings in the fields of pain research and the prevention and management of pain. Original research, reviews, symposium reports, hypothesis formation and commentaries are all considered for publication

\section{Dovepress}

The manuscript management system is completely online and includes a very quick and fair peer-review system, which is all easy to use. Visit http://www.dovepress.com/testimonials.php to read real quotes from published authors. 